\title{
Research on Social Capital and Conflict Management Mechanism of Family Business's Top Management Team
}

\author{
Jie $\mathrm{Lu}^{1}$, Xiajuan $\mathrm{Xie}^{1}$ \& Mengyun $\mathrm{Wu}^{2}$ \\ ${ }^{1}$ School of Management, Jiangsu University, P.R. China \\ ${ }^{2}$ School of Finance \& Economics, Jiangsu University, P.R. China \\ Correspondence: Jie Lu, School of Management, Jiangsu University, P.R. China. E-mail: lujie@mail.ujs.edu.cn
}

Received: April 12, 2013 Accepted: July 22, 2013 Online Published: August 30, 2013

doi:10.5539/ass.v9n11p70 URL: http://dx.doi.org/10.5539/ass.v9n11p70

\begin{abstract}
Social capital embedded in top management team decides knowledge, information and capacity of family enterprise's top management team, and emphasizes conflict management mechanism of TMT. The article analyzes social capital of TMT, conflict and conflict management mechanism, measures conflict management mechanism of TMT, states the relationship among inner social capital, firm-external social capital and conflict management mechanism of TMT, and prospects and future research.
\end{abstract}

Keywords: family enterprise, top management team, social capital, conflict management mechanism

\section{Introduction}

In the time of economic transition, Chinese family enterprise has faced the situation of lack of congenital resources controlling by the government and relationship orientation. Governments, enterprises and senior executives have established the rights, interests and relationships with Chinese characteristics and institutional factors such as TMT (Top Management Team)'s own social capital, relationships et al. on the one hand, the regulation and complement of formal institution play more and more important roles in enterprises' strategic decision, on the other hand, along with the rapid economic development, any organization will inevitably make a conflict, while family enterprise is conceived as a hotbed of conflict, from the fight for company control in GOME, Ford familial bar and Dartmouth group war traced back to the struggle between Thomas Watson senior and Watson Jr. in IBM group, family enterprises' disputes caused by the executive team are common. Therefore, how executives team take advantage of their own social resources external acquisition ability and internal exchange capacity to calmly deal with and effectively manage the increasing conflicts and contradictions is crucial to the team success and family enterprise success. In conclusion, the paper tries to embed the TMT members to executive team and organization of social structure instead of taking the executive team as a isolated whole or only as a single entity to state the function and significance of the internal and external social capital of TMT to the conflict management mechanism.

\section{Social Capital of TMT}

The contemporary social capital theory is inseparable of the contribution of Pierre Bourdieu, Coleman, Putnam, grand's victor and Bert et al, the research which differs from sociology, economics, and management forms the social capital concept jungle. In studies, the scholars focus social capital theory on particular levels, including individual levels (Burt, 1992), the level of organization (Leana, 1999) and industry levels (Walker, 1997) et al. But when studying social capital, the scholars did not do relatively effective integration analysis for each different levels of discuss; at the same time, though social capital theory is developing rapidly in social science, TMT's social capital theory is still very scarce, more focuses on using cognitive structure, trust, cohesion and several other factors to determine executive Teams' characteristics, but in some sense ignores TMT member's external open network connection (government, market, inside organization, and environment); In addition, in academic circles there is no agreement of opinion on the precise structure of social capital of TMT. Some researches (Burt, 2007) which are based on theories written by Nahapiet \& Ghoshal (1998), has defined three dimensions of social capital of TMT as team structure, team relations and team cognitive. Shipilov and Danis (2006) think for the first time that leaders and members of TMT divided social capital of TMT into two types: internal social capital (Bonding Social Capital), and external social capital (Bridging Social Capital) through the 
social relation network, which are based on trust and norms of ability of exchanging resources. From previous studies, we can infer that internal social capital has three dimensions such as structural, relational and cognitive, and external social capital can be divided into vertical connection, transverse connection and social connection; This paper focuses on special situation of China's "pattern of difference sequence" and "family culture", defines the accurate meaning of TMT's social capital, which can be defined as executive team which could achieve internal and external resources through its members in the team. Figure 1 is shown as follows.

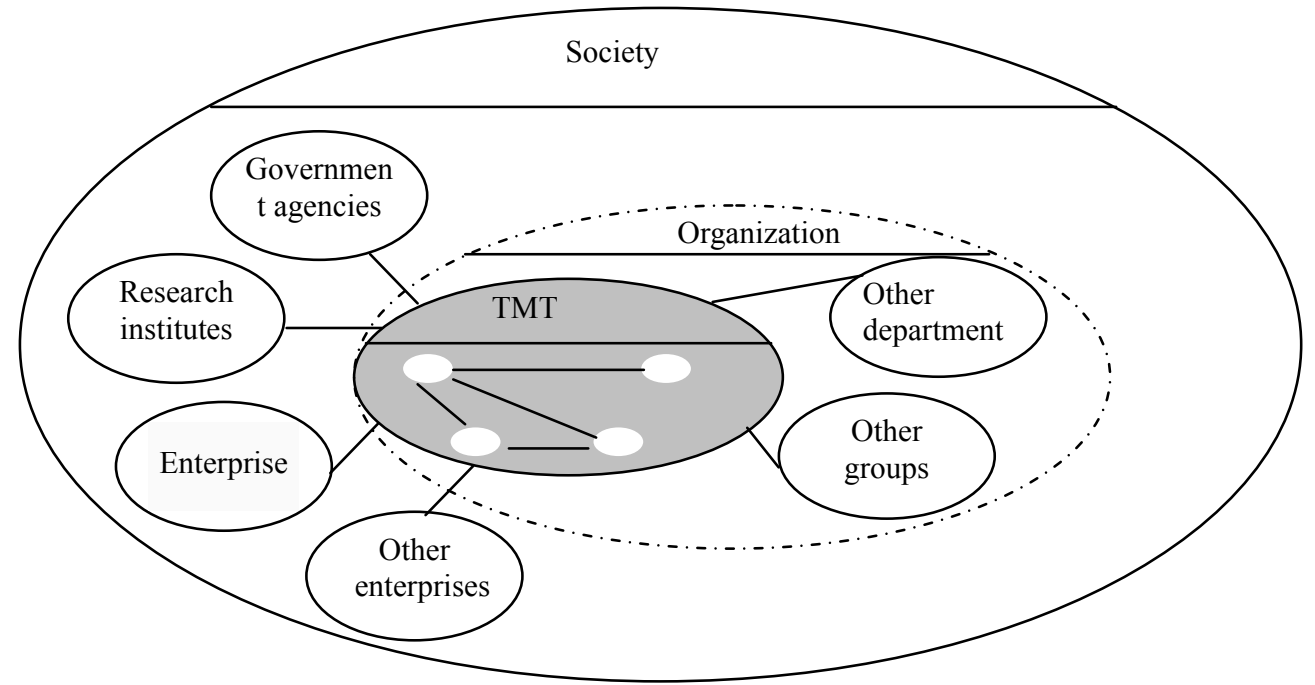

Figure 1. The definition of executive team social capital

As can be seen from Figure 1, the paper is different from the previous definition of social capital: firstly, the paper discusses executive team's external social capital which is rarely involved in existing research. TMT's external social capital refers to the external relation network and resources of team members especially the team leader, and external social capital can be divided into the team's longitudinal connection, transverse contact and social contact. Comparing with internal social capital, TMT's external social capital has greater liquidity and can timely acquire important informal working relationships and resources, such as information resources and political support. and other technical team within the organization between the longitudinal connection, the enterprise executive team and other enterprise executive team between the horizontal connection, executive team and government institutions, research institutes, enterprises such as customer contact closely. Secondly, the executive team has its unique internal social structure, the team may have multiple subordinate teams, but the goal demand should be consistent with the whole team goal demand, internal social capital itself has intrinsic features of ascending centripetal force and resisting conflict. In addition, it is worth noting that social capital and team also can bring expressive interests such as emotional supporting in addition to instrumental interests, which is less attended in the past study.

\section{Conflict of TMT and Its Management Mechanism}

\subsection{The Conflict of TMT}

Until now, scholars still have no clear and consistent view of concept of TMT's conflict. Jehn $(1996,2010)$ and Amason (1996) have representatively divided the TMT's conflict into tasks/cognitive conflict and relationships/emotional conflict. Due to the involvement of family factors, compared with the general business, family business executive's team conflict has its own specificity: (1) family businesses will face more and more internal conflict (Lee and Rogoff, 1996), and the conflict involves more complex aspects. The reason is that there are different systems of principles and values in family businesses, which are the family and the enterprise, the former emphasizes stability and equity, the latter aims at speed and profitability; (2) family business has a special dynamics of power system. Compared with typical enterprises controlled by professional managers, the family business has its own unique dynamics of power system (Sorenson, 1996; Thomason, 2005), and the scope of the conflict is far greater than the bureaucratic system; (3) the TMT's conflict easily leads to lock-in effect. This conflict is difficult to solve by a simple way to just let one of them go (especially when both of them are members of the family business).

\subsection{The Conflict Management Mechanism of TMT}


Researchers have made a lot of research on conceptual framework of conflict management mechanism on the level of individuals and teams. The study can be classified as follows: (1) the traditional unidirectional mode as Prisoner's Dilemma, which is relatively simple and lacks content validity and external validity; (2) multi-facts conflict resolution mode (Follett, 1940), which emphasizes more on the conceptual description and lacks empirical research; (3) bidirectional conflict resolution mode (Blake \& Mouton, 1964; Thomas \& Schmidt, 1976; Rahim, 2002), in which five-factor model (avoidance/forced/accommodate/cooperation/compromise) proposed by Thomas (1976) and five conflict management strategies (cognitive/diagnosis/analysis/processing/feedback) proposed by Rahim (2002) have wide impact. Both of them have clear conception and empirical research supports; (4) three dimensional conflict-resolution management model (Hersey \& Blanchard, 1988), which is more complex and seems to be immature. However, almost all the viewpoints agree that conflict management is not simple "disaster control", task conflicts are not always constructive; also relationship conflicts are not doomed to be destructive. Therefore, how to settle destructive conflict, enhance constructive conflict and promote the TMT management of the family business on a moderate and dynamic equilibrium conflict level will be valuable question to test.

Meanwhile, it is not common that the relevant research about measuring method of executive team conflict management mechanism. Thomas-Kimann (1976) developed Management of Differences Exercise Mode, Rahim (1983) developed Organizational Conflict Inventory, Jehn (1995) has proposed team Conflict Management scale and Jehn (2010) also proposed modification Suggestions. Recently, the distinctive research comes from Somech (2008) and Jehn (2010), they put forward the ASA (Attraction-Selection-Attrition, ASA) measurement model and think that destructive (FACE/avoidance/communication/force, FACE) or constructive (training/encourage/adjust/delay, TEPA) conflict management method should supplement each other and organically combine with conflict management process. The paper tries to integrate executive team conflict management mechanism of the conceptual framework and method of measurement.

\section{Research on Social Capital and Conflict Management Mechanism of Family Business's Top Management Team}

Existing research at home and abroad mostly focus on the relationship between executive team's internal social capital and conflict management mechanism, seldom involved the correlational study about external social capital of TMT (bridge) social capital and conflict management mechanism, therefore, the research tries to reflect the different influence on conflict management mechanism which respectively produced by executive team's external social capital (longitudinal connection, transverse contact and social contact) and internal social capital in three dimensions which are structure factors, relationship factors and cognitive factors

\subsection{Research on External Social Capital and Conflict Management Mechanism of TMT}

The process is a kind of system that the TMT members of family enterprises continuously participate in market activity and non-market activity, constantly expand and strengthen their social relation network, strengthen the team longitudinal and transverse connection with outside and optimizing the team's social capital. Park and Lou's (2001) found that external social capital of TMT such as the society relation among enterprise managers and other enterprise managers and government officials, may help strengthen constructive task conflict, reduce relationship conflict, optimize the conflict management and improve enterprise performance; Horne(2001) studied and confirmed that the core members of TMT-entrepreneurial external relationship cognition and relationship operation, the longitudinal connection of TMT's leader and the other general team in the business enterprise, the horizontal contact of enterprise executive team and other enterprise executive team, with its appearance non-repeatability and disadvantages characteristic to promote the diversity and integration of network with limited resources, it is helpful for execution of team external's standard and make great influence on the conflict management mechanism and then help to effectively deal with the team conflict; Turman (2003), Doherty (2011) argued that social capital is a very strong predictor variable of TMT, and have measured the external social capital of TMT and thought that the external social capital of TMT more performance for cross-border reality and potential resources, the diversity and heterogeneity and non redundancy of information and support that the team get from other departments within the organization, the team which is outside of organization or has more social contacts will be stronger and helpful to make innovative decision and then strengthen cohesion; at the same time, some scholars believe that the existence of team external social capital will make TMT members more easily to be involved in team activities and to struggle for the success of the team, and there is less absence and resign phenomenon and then can make the TMT members prefer to communicate with each other, with the guidance of interactions among internal members of the team, TMT members can put less effort in maintaining team relations and put more effort to expand external networks and into the new group (Burt, 2007). In conclusion, to eliminate conflict, executive management of external social capital of TMT 
members will at least lie in the following aspects: (1) getting social support for administrative resources. Due to the team members lie in the enterprise's core position and master more resources, cross boundary interactive behavior will help the team acquire more administrative resources support and improve the ability to resolve external political pressure and then effectively level team contradiction; (2) gaining informal information resources from other teams within the organization. In addition to related to the formal power layer phase of the team, the contact with other team or organization of the informal leader is one of the key channels of acquisition for external social resources of TMT. Keeping good relationships with these informal leader helps the team to get support from the internal and external members when it is needed and reduce the friction between each other, (3) Enhancing communication with other executive team out of the organization, promoting the organization members' cooperation. Effectively protect team from external threat, thus forming an effective and efficient external transverse relation network in limited manpower and material resources situation.

\subsection{Research on Internal Social Capital and Conflict Management Mechanism of TMT}

\subsubsection{Structural Social Capital and Conflict Management Mechanism}

Structural social capital depends on the degree of social interactions among team members, almost all the study of the TMT will be measured by longitudinal level of "interaction strength" and transverse level of "network density" (Jehn, 2010). Considering the characteristics of decision-making executives team, the structural social capital of TMT can be measured by "informal changeable communication degree" and "network density" : on the one hand, the changing of informal communication refers to "the preference that the team members reflect to informal chemical interaction", namely ,the number of communication among members in a certain period in informal ways, in the family enterprise organization situation, interpersonal communication tend to follow the "customs law", patriarchal "kindness leadership" also emphasize that the mercy to the lower should be expanded to the phase of subordinate family and personal question, therefore, the informal communication in family enterprise TMT is not uncommon. When team members appear disagreement, informal communication depends on spontaneous conversation, unstructured meetings and gatherings to exchange opinions and extends exchange to relatively private areas which can promote recognition and trust between members and avoid positive conflict of team members, it is also helpful for the combination and exchanging of information and resources in internal team and improve the effect of conflict management. Therefore, in Chinese family enterprise, TMT member who treats "harmony" as the core values, informal communication can be extremely and effectively promotes the level of constructive task conflict and then stimulates team members to produce heterogeneous and diversified view (Li, 2009); On the other hand, the network density refers to the common contact degree among team members in a certain level, which reflects the concentration of internal consultation network, friendship network or communication network in level of the organization size. The height of network density can reflect circle phenomenon within the team. There is no circle in higher density network and it appears high interaction frequency, high emotional density, high trust degree and strong cohesion between the team members which forms relatively typical strong relation network and then reduces opportunism behavior in the decision information exchange and stimulates the task conflict and reduces conflict relationship; besides, the existence of the circle will reduce the density of team internal network, the member in decision-making process tend to protect themselves or interests of the circle which they belonged to and control, conceal relevant decision information, and produce negative influence on conflict management (Sharma, 2004; Baron, 2008) .

\subsubsection{Relational Social Capital and Conflict Management Mechanism}

Relational social capital reflects the emotion quality of contact between members, which can be measured by interpersonal trust, obligations and expectations, common norms and identity mark in related studies, the trust is generally thought as the core elements of relational social capital. TMT trust refers to the will that the team members take risks for the team's overall decision results, which includs making co-operations, sharing information and allowing to be controlled by the team among team members. The positive role that trust plays on the effect of conflict management has been widely confirmed. Hambrick (1984) found that in the high trust degree team, the members have positive expectations and understanding for others' behavior and be more open and comprehensive in the conflict management process, which is helpful for sharing and exchanging diversify information to achieve effective decision. Moreover, the higher trust degree team easily reaches an agreement in the common strategic target in the process of conflict management. Simons \& Peterson (2010) argued that, the lower trust degree team need to spend a lot of time and energy for target coordination and exchange of information and hard to reach an agreement, but the higher trust degree team can be focused on the task process and then may appears more task oriented constructive task conflict and obtain a higher quality decision and satisfaction; Olson (2007) also found that trust can increase the angle of view that the team members analysis and solve problems and promote the implementation of the strategic decision and improve target's execution 
dynamics, effectively relieve team members personal hostility and tension.

\subsubsection{Cognitive Social Capital and Conflict Management Mechanism}

Cognitive social capital reflects the association cognitive quality between members in network, which is the deepest content of the social capital (Bercovitch, 2011). It is measured by "common vision", which is forming the unified cognition and commitment for collective goal and mission between team members, making them produce consensus for the possible results of different action, while this expectations is the basic of cooperation. Executives group the decision- making process of TMT is a complex and subtle political process that occur bargaining and mutual conflicts and mutual compromise between various interest groups. At the same time, senior executives especially CEO may be replace the collective goal of enterprise or team with personal irrational target. Common vision as a unified cognitive paradigm can strengthen the ability and the wish that the TMT members harmonize and unify their personal goals with collective goal and prompted him to become the rational agent of collective goal and make behavior promise to achieve the goal: on the one hand, the common vision enhances the team's cohesion, improves the network density, makes opportunism tendency between members under control, provides a clear framework for information exchange, improves the degree of information sharing in the team and improves the conflict management quality, On the other hand, TMT members who have common goal, similar norms and values are easy to set up trust, form the harmonious cooperation and eventually improve the conflict management mechanism.

\section{References}

Amason, A. C. (1996). Distinguishing effects of functional and dysfunctional conflict on strategic decision making: Resolving a paradox for top management teams. Academy of Management Journal, 39(1), 123-148 http://dx.doi.org/10.2307/256633

Burt, R. S. (2007). Teaching Executive to See Social Capital: Result From a Field Experiment. Social Science Research, (36), 28-29.

Doherty, L., \& Teague, P. (2011). Conflict management systems in subsidiaries of non-union multinational organisations located in the Republic of Ireland. International Journal of Human Resource Management, 57-71. http://dx.doi.org/10.1080/09585192.2011.538968

Dyer, W. G. J. (2003). The family: The missing variable in organizational research. Entrepreneurship Theory and Practice, 27(4), 401-416. http://dx.doi.org/10.1111/1540-8520.00018

Ensley, M. D., Pearson, A. W., \& Amason, A. C. (2002). Understanding the dynamics of new venture top management teams: Cohesion, conflict, and new venture performance. Journal of Business Venturing, 17 (4), 22-34. http://dx.doi.org/10.1016/S0883-9026(00)00065-3

Hambrick D. C., \& Mason P. A. (1984). Upper Echelons: The Organization as a Reflection of Its Top Managers. Academy of Management Review, (9), 193-206.

Jehn, K. A., Rispens, S., Thatcher, S. M. B. (2010). The effects of conflict asymmetry on work group and individual outcomes. Academy of Management Journal, 596-616. http://dx.doi.org/10.5465/AMJ.2010.51468978

Olson, B. J., Parayitam, S., \& Bao, Y. (2007). Strategic decision making: The effects of cognitive diversity, conflict, and trust on decision outcomes. Journal of Management, 33(2), 196-222. http://dx.doi.org/10.1177/0149206306298657

Rahim, M. A. (2002). Toward a theory of managing organizational conflict. International Journal of Conflict Management, 13(3), 206-235. http://dx.doi.org/10.1108/eb022874

Sharma, P. (2004). An overview of the field of family business studies: current status and directions for the future. Family Business Review, 17(1), 1-36. http://dx.doi.org/10.1111/j.1741-6248.2004.00001.x

Sun, C. M., \& Sun, J. H. (2008). Entrepreneurs population background characteristics and enterprise diversification strategy choice. Management world, (5), 24-35.

Zhou, X. H., \& Ma, L. (2008). Enterprise social capital, cultural orientation and exit intend to - based on localization psychology view of empirical research. Management world, (6), 109-117.

\section{Copyrights}

Copyright for this article is retained by the author(s), with first publication rights granted to the journal.

This is an open-access article distributed under the terms and conditions of the Creative Commons Attribution license (http://creativecommons.org/licenses/by/3.0/). 